\title{
Nodose Placode Contributes Autonomic Neurons to the Heart in the Absence of Cardiac Neural Crest
}

\author{
Margaret L. Kirby \\ Department of Anatomy, Medical College of Georgia, Augusta, Georgia 30912
}

\begin{abstract}
The objective of this research was to determine the origin of the cholinergic neurons that populate the heart following ablation of the neural crest area, which normally gives rise to the cardiac ganglia. Using ablation of various areas of surface ectoderm-including neural crest migrating to the heart, nodose placode, and neural crest plus nodose placode-it was determined that regeneration of the neural component of cardiac neural crest did not occur in the absence of the nodose placodes. When cells from the nodose placode were followed in quail to chick chimeras of nodose placode with ablated cardiac neural crest, quail nodose placodederived neurons were found in the cardiac ganglia. These results explain the "regeneration" of cholinergic cardiac ganglia in embryos lacking cardiac neural crest.
\end{abstract}

The peripheral nervous system is derived from neural crest and ectodermal placodes (Narayanan and Narayanan, 1980; d'Amico-Martel and Noden, 1983; reviewed by LeDouarin, 1986, and LeDouarin et al., 1986). In the trunk, the neural crest gives rise to all of the peripheral neurons, as well as supporting cells and Schwann cells (Horstadius, 1950; LeDouarin, 1982). However, in the head, the derivation of the peripheral neurons is divided between the neural crest and a series of placodes that form lateral to the neural tube (d'Amico-Martel and Noden, 1983). The neural crest provides all of the supporting and Schwann cells for cranial ganglia regardless of the origin of the neurons (d'Amico-Martel and Noden, 1983). All of the autonomic neurons without exception have been shown to arise from neural crest precursors (Horstadius, 1950; LeDouarin, 1982). The cranial sensory ganglia, however, are mixed in origin. The trigeminal (V) and geniculate (VII) ganglia have neurons that are derived from the neural crest and placodes. In these ganglia, the neural crest-derived neurons are always proximal to the placode-derived neurons. The pattern of the other ganglia of mixed origin (IX, X) is similar in that the neurons of the proximal ganglia arise from the neural crest, while the neurons of the more distally placed ganglia arise from placodal regions approximately lateral to the neural crest anlage of the proximal ganglion (d'Amico-Martel and Noden, 1983). As stated above,

Received Dec. 29, 1986; revised Sept. 8, 1987; accepted Sept. 10, 1987

I would like to thank Dale Bockman for helpful suggestions on directing these experiments and for the critical review of the manuscript, and Harriett Stadt and George Forbes for technical assistance. This work was supported by PHS Grant HD 17063 and was done during the tenure of an Established Investigatorship for the American Heart Association with funds contributed in part by the Georgia Affiliate.

Correspondence should be addressed to Dr. Kirby at the above address.

Copyright (c) 1988 Society for Neuroscience $0270-6474 / 88 / 041089-07 \$ 02.00 / 0$ the supporting cells are always of neural crest origin regardless of the origin of the neurons (d'Amico-Martel and Noden, 1983).

The heart derives innervation from 3 sources (Fig. 1). (1) Sympathetic innervation is via the first thoracic sympathetic ganglia, which are derived entirely from neural crest (Baumel, 1975; Kirby and Stewart, 1984). (2) Parasympathetic innervation is from cardiac ganglia that are derived from neural crest adjacent to somites 1-3 (Kirby and Stewart, 1983). (3) Sensory innervation of the heart is from the distal ganglia of the vagus nerve (Wakley and Bower, 1981). The neurons of these ganglia arise from the nodose placodes located lateral to somites 1-3 (d'Amico-Martel and Noden, 1983). The supporting cells of these ganglia are provided by neural crest located approximately adjacent to the caudal otic placode region to somite 3 (d'AmicoMartel and Noden, 1983).

The area of neural crest that seeds the heart with cholinergic parasympathetic postganglionic neurons has been shown to provide ectomesenchymal cells to the outflow tract (Kirby et al., 1983). This region of the neural crest extends from the otic placode to the caudal limit of somite 3 and has been designated "cardiac neural crest" (Kirby et al., 1985a). Removal of the cardiac neural crest results in persistent truncus arteriosus, a condition in which the outflow vessel of the heart remains undivided (Nishibatake et al., 1987). Persistent truncus arteriosus following cardiac neural crest ablation accompanies a small decrease $(30 \%)$ in the parasympathetic postganglionic innervation of the heart, even though studies using chimeras have shown that all of the cardiac neurons are normally derived from the cardiac neural crest (Kirby et al., 1985b). This result has been interpreted as a regeneration or compensation of the neural component of cardiac neural crest without a concomitant regeneration of the ectomesenchymal component.

Attempts have been made in this lab to remove very long lengths of neural crest and neural tube in order to identify the regions that contribute to this neural compensation. These attempts have been unsuccessful (unpublished data).

This report shows that the cholinergic neurons that appear in the heart after neural crest ablation arise from the nodose placode.

\section{Materials and Methods}

Animal preparation

Fertilized Arbor Acre chicken eggs were obtained fresh from the hatchery (Seaboard Hatcheries, Athens, GA). Fertilized quail eggs were obtained from a colony of Japanese quail maintained in the Medical College of Georgia animal facility. The eggs were incubated in force-draft incubators maintained at $38^{\circ} \mathrm{C}$ and $95 \%$ humidity. The eggs were opened at about $30 \mathrm{hr}$ of incubation, which produced embryos at Hamburger- 


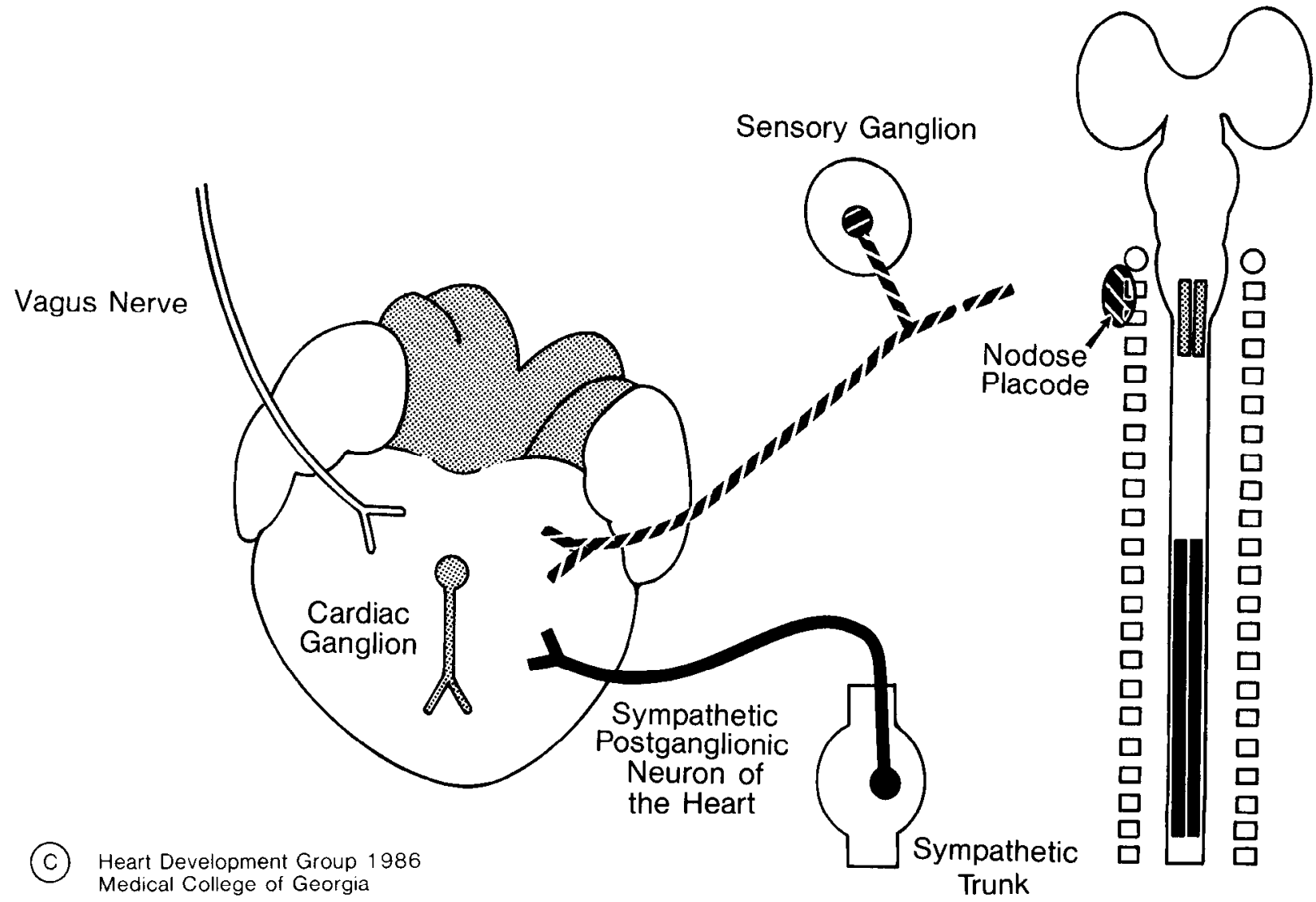

Figure 1. Diagram mapping the origin of the various components of the cardiac innervation. The sensory innervation arises from the nodose placode; parasympathetic postganglionic cholinergic neurons (cardiac ganglia) arise from neural crest adjacent to somites 1-3; sympathetic postganglionic adrenergic neurons arise from the neural crest adjacent to somites $10-20$.

Hamilton stages 8-11. All embryos were prepared by microsurgery according to the method of Narayanan (1970).

\section{Microsurgery}

Two types of microsurgery were performed: ablation of various areas of the embryonic ectoderm and transplantation of quail ectodermal placodes onto chick hosts with subsequent ablation of other regions.

Ablation. Ablations were performed using a microcautery unit designed and built by the Department of Biomedical Engineering at the Medical College of Georgia. Three types of experimental embryos were produced, in addition to a complete series of sham-operated embryos. For shams, each embryo was stained with neutral red and the vitelline membrane over the embryo was torn. The eggshell window was covered using cellophane tape and the egg returned to the incubator. In the experimental series the cardiac neural crest was ablated (neural crest extending from the midotic placode to the caudal boundary of somite 3 ), the region of the nodose placode was ablated, or finally both cardiac neural crest and nodose placodes were ablated.

Transplantation. Two types of chimeric embryos were produced. Placodes were transplanted as described by d'Amico-Martel and Noden (1983). Using electrolytically sharpened tungsten needles, the area of ectoderm lateral to somites $1-3$ was stripped unilaterally from stage 9 or 10 chick embryos. The comparable area of ectoderm from stage 7 or 8 quail embryos (Zacchei, 1961) was dissected away from the underlying lateral plate mesoderm and transferred to the chick embryo. The quail ectoderm was carefully placed right-side-up onto the prepared site in the chick embryo. The eggs were sealed and returned to a holding incubator for 4-5 hr.

The egg was again opened, and if the grafted ectoderm was observed to be tightly adherent to the chick embryo, the second stage of the surgery was performed. Embryos in which the graft was not adherent were discarded.

In half of the retained embryos the egg was sealed and returned to the incubator. These embryos were designated chimera-shams. In the other half of the chimeras, the cardiac neural crest and the contralateral nodose placode were ablated using microcautery. The contralateral nodose placode was ablated to reduce the number of non-quail cells that migrate to the heart. However, in the absence of contralateral nodose placode ablation, the result was qualitatively the same.

\section{Acetylcholinesterase histochemistry}

AChE histochemistry was used to visualize the cardiac ganglia remaining on the surface of the heart after ablations. The method of Rickenbacher and Muller (1979) shows the distribution of the cholinergic components of the cardiac plexus on the surface of whole hearts. On the eleventh or twelfth day of incubation, embryos were perfused intracardially with cold $10 \%$ neutral-buffered formalin. The hearts were removed, postfixed for $30 \mathrm{~min}$, and washed in distilled water. Cholinesterase was demonstrated using the Karnovsky and Roots (1964) method. The hearts were stored in neutral-buffered formalin for photography.

\begin{tabular}{llll}
\hline Table 1. Viability of embryos after various ablations \\
& \multicolumn{4}{c}{$\begin{array}{l}\text { Survived to } \\
11-12 \text { d of } \\
\text { incubation }\end{array}$} & $\begin{array}{l}\text { Viability } \\
(\%)\end{array}$ \\
Group & Operated & 14 & 56 \\
Sham & 25 & 5 & 50 \\
Nodose placode & 10 & 5 & 22 \\
Cardiac neural crest & 23 & 12 & 13 \\
Cardiac neural crest & & & \\
$\quad$ and nodose placode & 93 & & \\
\hline
\end{tabular}



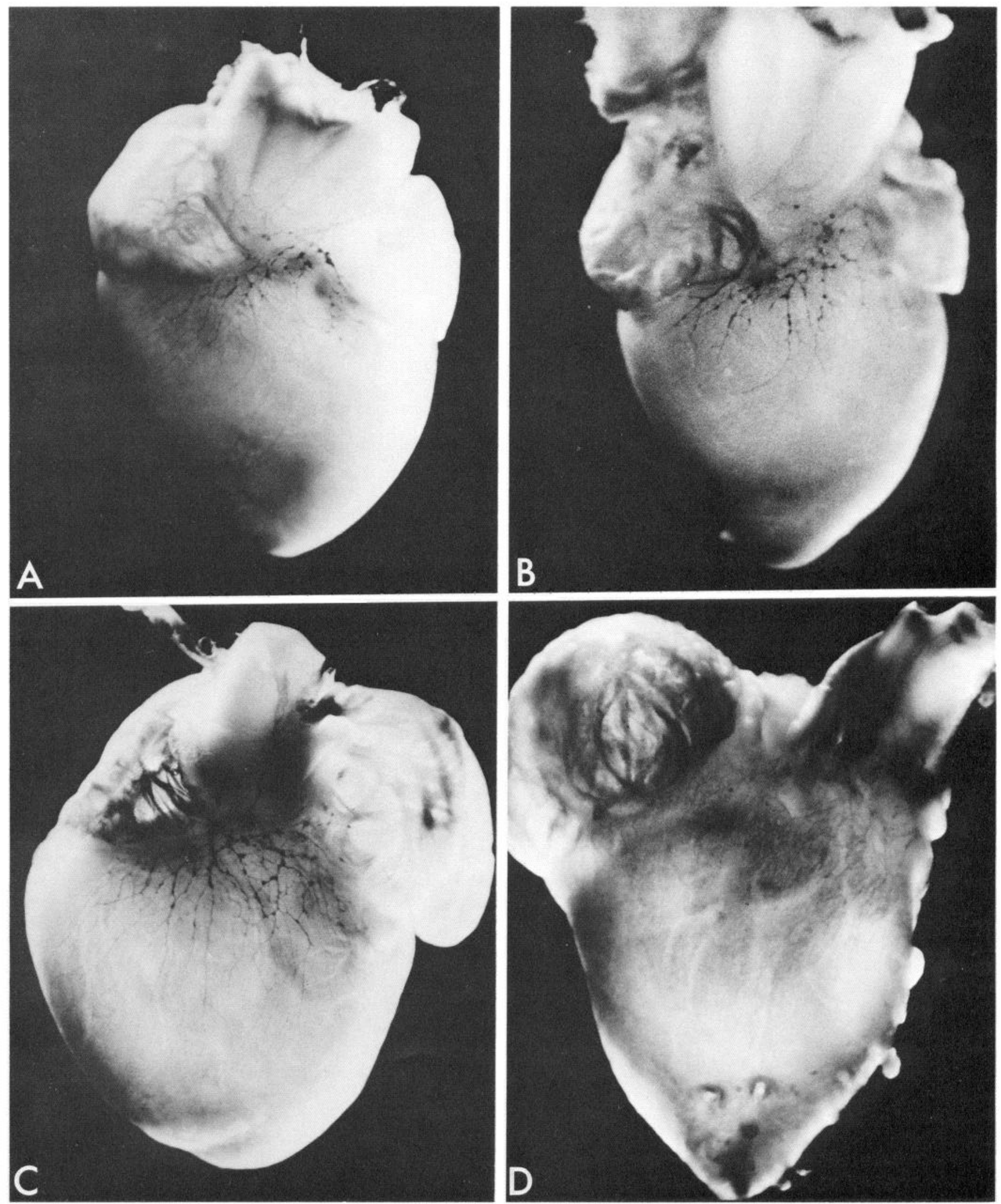

Figure 2. AChE-stained whole hearts from embryos on day 12 of incubation. The cholinesterase-positive structures are the parasympathetic portion of the cardiac plexus. Only ventral views are shown. $A$, Sham. $B$, Nodose placodes ablated bilaterally. $C$, Cardiac neural crest ablated. $D$, Cardiac neural crest and nodose placodes ablated. The sham- and nodose placode-ablation hearts are structurally normal, while the heart with cardiac neural crest ablation has persistent truncus arteriosus. The heart with the combined ablation has persistent truncus arteriosus and shows a left $(L)$ rather than right $(D)$ loop configuration. 


\section{Histological evaluation}

Hearts in which cholinesterase had been visualized, as well as chimeric cmbryos, were processed for examination using light microscopy. Chimeras were collected on days 5-9 of incubation by immersion fixation in Carnoy's fixative. Hearts or embryos were dehydrated, embedded in paraffin, sectioned, mounted, and stained using the Feulgen and Rossenbeck stain (1924) for chimeras and thionin staining for hearts previously treated for cholinesterase demonstration.

\section{Choline acetyltransferase immunohistochemistry}

Immunostaining was carried out according to the peroxidase-anti-peroxidase (PAP) method of Sternberger (1979). Briefly, hearts were perfused intracardially with cold saline followed by $4 \%$ paraformaldehyde in PBS. The outflow area and the nodose ganglia were postfixed for 30 min and frozen in isopentane cooled in liquid nitrogen. Ten micrometer cryostat sections were mounted on gelatinized slides and stained using a 1/200 dilution of CAT derived from rat hybridomia (Immunonuclear) as the primary antiserum. The secondary antiserum was rabbit anti-rat $\mathrm{IgG}$ (Sigma), with rat PAP (Polyscience) as the third antiserum. Control sections were processed using normal rat $\mathrm{IgG}$ in place of the CAT antibody.

\section{Results}

\section{Neural crest ablations}

Thirty-six embryos were analyzed for the ablation portion of the experiment. Overall viability was $24 \%$. The embryos' group viabilities are shown in Table 1 . Survival in embryos with nodose placode ablations was similar to that with sham surgery. Removal of cardiac neural crest reduced the viability by $50 \%$. It has been shown previously that removal of cardiac neural crest results in persistent truncus arteriosus with hypoplasia or atresia of the great vessels (Nishibatake et al., 1987). This probably accounts for the increased mortality following cardiac neural crest ablation. Removal of cardiac neural crest and nodose placodes resulted in an even greater decrease in viability of the embryos.

Figure 2 shows the effects of the various ablations on the cholinergic cardiac plexus. The hearts are stained for wholeorgan demonstration of cholinesterase. Removal of the nodose placodes alone did not significantly affect the distribution or size of the cardiac plexus, nor did it affect the normal development of the cardiac outflow tract. Removal of the cardiac neural crest did not result in a visible depletion of the cholinergic cardiac plexus. From past studies using a variety of quantification techniques, a $30 \%$ decrease has been demonstrated, even though it is not apparent in Figure $2 C$ (Kirby et al., 1985b). Paradoxically, the removal of the cardiac neural crest is thought to be complete because of the presence of persistent truncus arteriosus in the heart (Fig. 2C). This indicates that the ectomesenchymal cells that arise from cardiac neural crest cells are not present in the outflow tract. Removal of the cardiac neural crest, as well as of the nodose placode, results in the absence of the cholinergic cardiac plexus. The heart is structurally very primitive. Embryos with this lesion did not live beyond $12 \mathrm{~d}$ of incubation in this series of experiments, but the reason for this is not immediately apparent.

Serial section analysis confirmed the observations made using whole hearts (Fig. 3). Abundant ganglia were found in the sham hearts and after nodose placode or cardiac neural crest ablations. The ganglia were identical in shams and after nodose placode ablation. After cardiac neural crest ablation there was a paucity of supporting cells in the ganglia, and the extracellular matrix in the ganglia was very condensed. A few scattered cardiac ganglia were found in hearts with ablation of cardiac neural crest and nodose placodes. These ganglia contained a sparse population of neurons, which were strongly positive for cholinesterase.

$\mathrm{AChE}$ is not a specific marker for cholinergic neurons, as many neurons show positive staining for this enzyme but do not synthesize ACh. Hence, the possibility exists that the neurons in the cardiac plexus that are demonstrated using cholinesterase histochemistry are not actually cholinergic. When hearts from embryos that lacked cardiac neural crest were stained using $\mathrm{CAT}$, all of the neurons of the cardiac plexus reacted positively (Fig. 4). On the other hand, neurons of the distal vagal ganglion did not show any staining with CAT antibody.

\section{Chimeras}

A total of 95 chimeras was produced. Approximately half were used as shams and the other half had cardiac neural crest and contralateral nodose placode ablation. Twenty-three chimeric embryos were collected on incubation days $6-9$. These included 11 chimera-shams and 12 chimera-ablated embryos; this was a viability of $24 \%$. Even though the graft was confirmed as being adherent at the time of surgery, in about $50 \%$ of the embryos, the distal vagal ganglion was not present or was not labeled. These embryos were excluded from further study. In 6 chimerasham embryos that were included in the study, the distal vagal ganglion was found to be composed of quail neurons with chick supporting cells on the side of the transplant (Fig. 5). On the contralateral side, the ganglion consisted of chick neurons with chick supporting cells. No quail cells could be found in the heart or near the outflow vessels, nor were any quail cells found in any of the other cranial ganglia.

In 6 chimeras that had the cardiac neural crest and contralateral nodose placode ablated, the ipsilateral distal vagal ganglion consisted largely of quail neurons, with few supporting cells (Fig. 4). The contralateral distal vagal ganglion was usually small or absent. Cardiac ganglia in the heart consisted of quail neurons, with a sparse population of chick supporting cells, indicating that the cardiac neural crest ablation was incomplete, but only marginally.

Although it is possible that a few neural crest cells left the neural fold at the level of the cardiac neural crest by stages 78 in the quail embryo, it is unlikely that any significant number of neural crest cells are transplanted along with the nodose placode. However, it is likely that underlying mesodermal cells are transplanted with the placodal ectoderm. In several of the chimeric embryos, the myocardial cuff of the outflow region showed quail myocardial cells. This occurred even when the inferior ganglion of the vagus was absent. Since the myocardium is never labeled following neural crest transplantation, these myocardial cells are thought to arise from the mesoderm attached to the transplanted placode.

\section{Discussion}

These results clearly indicate that cells derived from the nodose placodes populate the heart with cholinergic neurons in the absence of the neural crest precursors for the cholinergic cardiac plexus. Under ordinary circumstances the cells of the nodose placode provide sensory innervation to the heart via the distal ganglia of the vagus (Wakley and Bower, 1981). The cholinergic cardiac ganglia provide parasympathetic innervation to the heart. In the current experiment, cells destined for a sensory ganglion have appeared in motor ganglia and express motor neuron phe- 

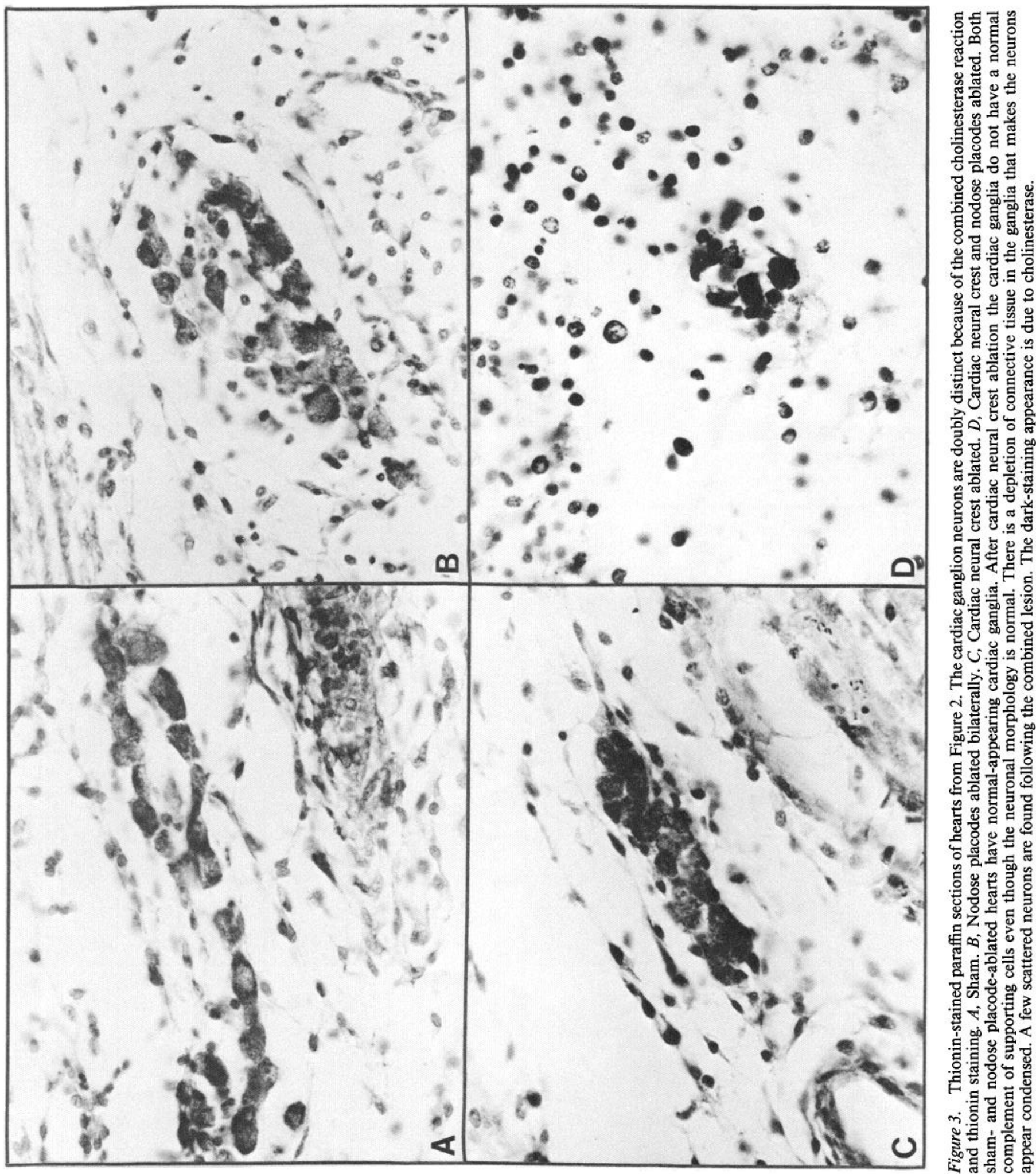


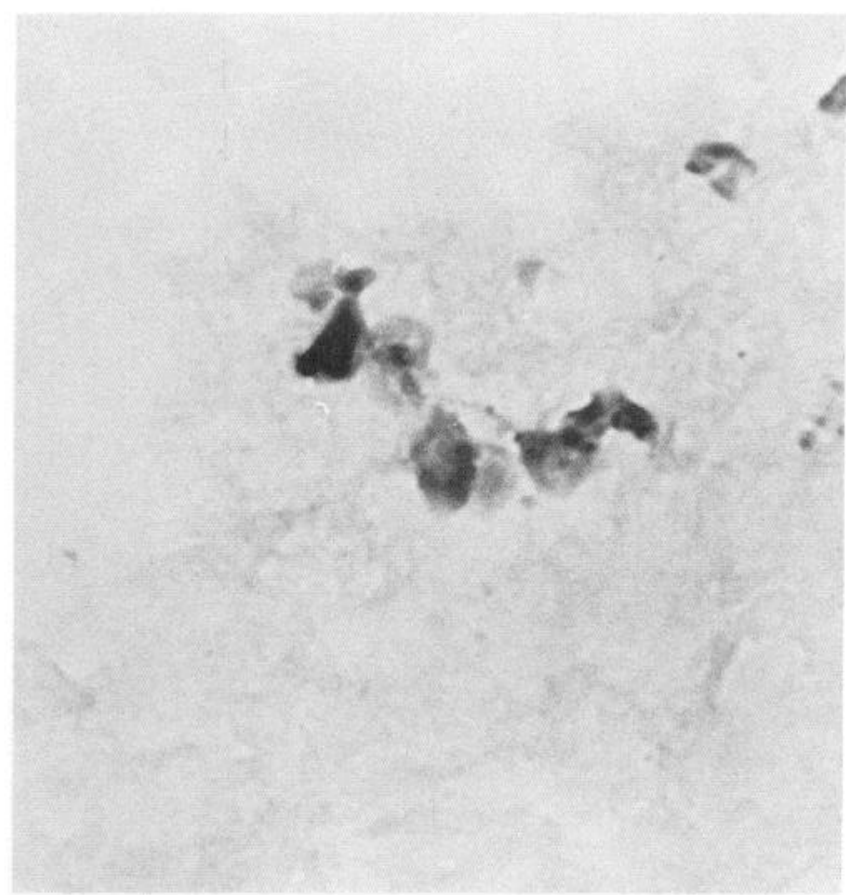

Figure 4. Choline acetyltransferase localization in a small cardiac ganglion from a day 14 chick embryo whose cardiac neural crest was removed at $30 \mathrm{hr}$ of incubation. notype. Of course, the present experiment does not show whether the phenotypically motor neurons are functional. It is not clear from these experiments whether sensory precursors actually undergo a change in their prospective fate. The capabilities of placodal cells have not been well characterized. Placodal cells may represent a multipotential class of cells similar to the neural crest. This possibility is supported by the fact that placodal cells are capable of providing ectomesenchymal cells to the heart in the absence of cardiac neural crest (Kirby, 1988).

The primary transmitter of the sensory ganglia has not been firmly established, although $\mathrm{ACh}$ has been ruled out as a primary afferent transmitter. The most likely sensory transmitter at present is glutamate or some modified form of glutamate (Davidoff, 1983). Substance $P$ has also been identified in a small population of neurons in the distal vagal ganglion (LeDouarin, 1982). Conversions of neuronal phenotype from cholinergic to adrenergic and from adrenergic to cholinergic have been demonstrated in several experimental paradigms (Patterson and Chun, 1977; Ayer-LeLièvre and LeDouarin, 1982; Landis and Keefe, 1983). This type of neuronal phenotypic plasticity occurs readily among sympathetic and parasympathetic derivatives of the neural crest (see LeDouarin, 1986, for review). Experiments of this type have been used to show that the neuronal environment plays a role in the neuron's final choice of transmitter phenotype.

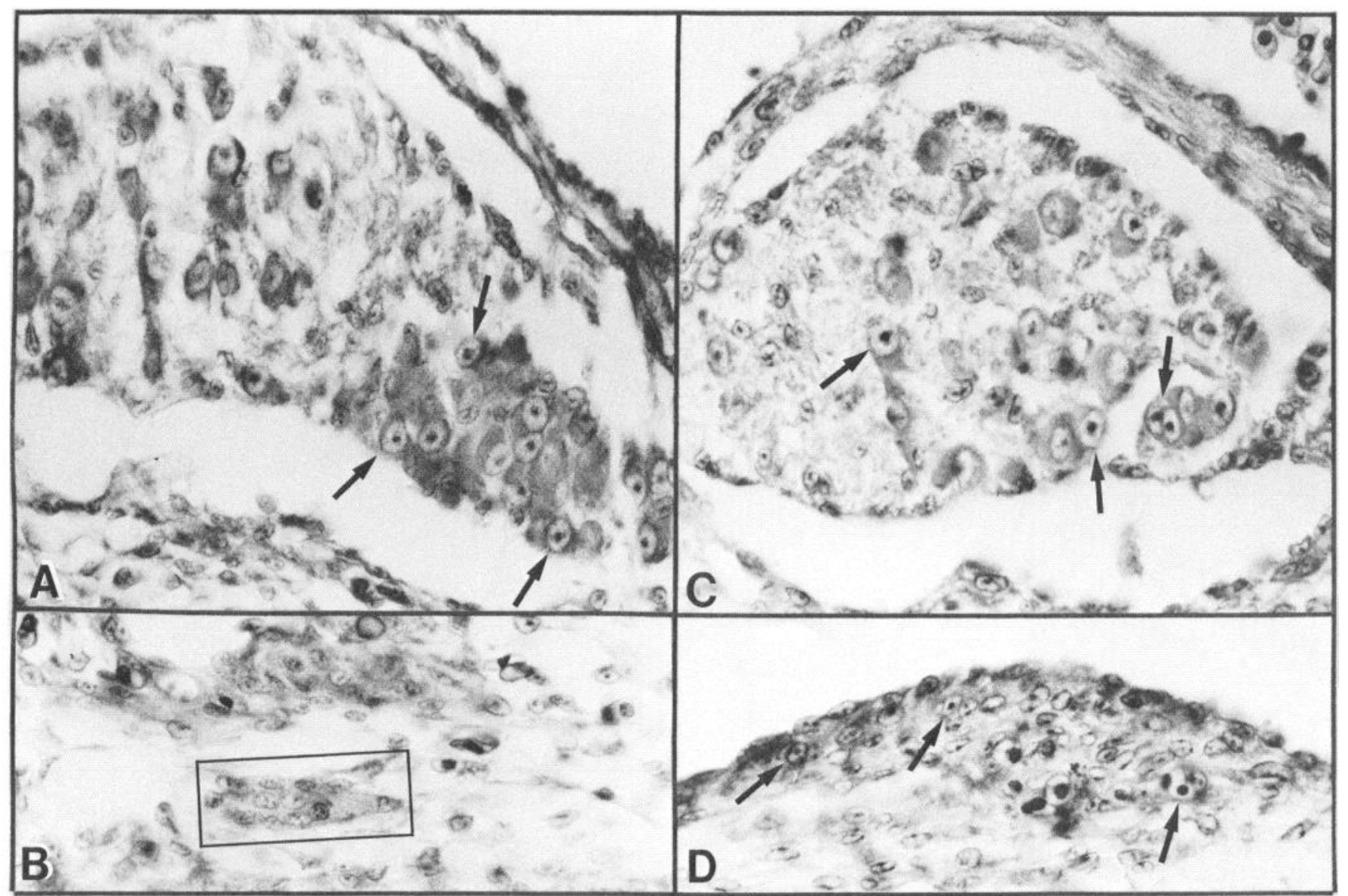

Figure 5. Feulgen and Rossenbeck-stained paraffin sections of quail to chick chimeras of the nodose placode. $A, B$, Left distal vagal ganglion and a cardiac ganglion of a chimera sham. Quail cells are apparent in the vagal ganglion (arrows), but are not present in the cardiac ganglia (box in $B$ ). $C, D$, Left distal vagal ganglion and a cardiac ganglion of a chimera that had the cardiac neural crest ablated following transplantation. Both the distal vagal ganglion and the cardiac ganglion contain quail cells (arrows). 
Environmental cues must play a role in the choice of transmitter phenotype made by neuronal derivatives of placodes as well. That the placode-dcrived neurons of the cardiac plexus are cholinergic is shown in the present paper by the presence of CAT in placode-derived cardiac ganglia. CAT is not present in the neurons of the distal vagal ganglia. In a separate study in which ACh was measured (Kirby et al., 1985b), the ACh content of the heart matched the ganglion cell number in the outflow tract in controls and following ablation of the cardiac neural crest.

It has been a source of confusion that the cardiac plexus is only diminished by $30 \%$ following cardiac neural crest ablation (Kirby et al., 1985b). Attempts to remove the cardiac plexus have included removal of the neural crest from the diencephalon to somite 26 and removal of the neural crest and neural tube from the diencephalon to somite 26 . In both cases, mortality was very high, but the cardiac plexus was present and in several instances increased (M. L. Kirby, unpublished observations). This indicates that regeneration of the cardiac plexus does not derive from the neural crest or neural tube. Removal of cardiac neural crest results in a high incidence of persistent truncus arteriosus. The structural defect in cardiac development is due to the absence of the ectomesenchymal component of the cardiac neural crest. Although it has recently been demonstrated that non-neuronal cells from the nodose placode become incorporated into the wall of the truncal vessel, these cells are not able to septate the outflow tract (Kirby, 1988). This seems to explain the "regeneration" of the cardiac plexus without concomitant regeneration of the ectomesenchymal components of the cardiac neural crest.

The viability of sham embryos produced from this laboratory has ranged from 50 to $70 \%$. It is interesting that viability of embryos following nodose placode ablation is similar to that of sham embryos. No cardiac abnormalities were noted following placode ablations and this probably contributed to their viability. The viability of embryos with ablations of the entire cardiac neural crest has traditionally been low, especially when the experiments have involved embryos at days 10-15 of development (Kirby et al., 1985b). It is thought that this high mortality is due to the serious nature of the intracardiac defects, as well as to the fact that many of the aortic arch arteries do not persist following ablation of cardiac neural crest (Nishibatake et al., 1987). Removal of nodose placodes along with cardiac neural crest decreases viability even further. The reason for this is not entirely clear. It is possible that vagal innervation is necessary for further physical or functional development of the heart. This is an attractive possibility because of the coincidence of onset of vagal function with death of these embryos at day 12. However, the nodose placode also provides mesenchymal components to the outflow tract of the heart and to the persisting arch arteries. In the absence of cardiac neural crest and nodose placode cells, the structural abnormalities of the heart are significantly more severe (Kirby, 1988). This may explain the rather abrupt death of these embryos at day 12 .

Although it has traditionally been thought that the neural crest regenerates cells from the regions cranial and somewhat caudal to an ablated area (Yntema and Hammond, 1945; McKee and Ferguson, 1984), regeneration of the cardiac neural crest by other neural crest cannot be demonstrated. The nodose placode appears to provide a regenerative region for the neural component of the cardiac neural crest.

\section{References}

Ayer-LeLièvre, C. S., and N. M. LeDouarin (1982) The early development of cranial sensory ganglia and the potentialities of their component cells studied in quail-chick chimeras. Dev. Biol. 94: 291-310.

Baumel, J. J. (1975) Nervous system. In The Anatomy of the Domestic Animals, R. Getty, ed., Saunders, Philadelphia, PA.

d'Amico-Martel, A., and D. M. Noden (1983) Contributions of placodal and neural crest cells to avian cranial peripheral ganglia. Am. J. Anat. 166: 445-468.

Davidoff, R. A. (1983) Handbook of the Spinal Cord, Marcel Dekker, New York

Feulgen, R., and H. Rossenbeck (1924) Mikroskopisch-chemischer Nachweis einer Nucleinsaure vom Typus der Thymonucleinsaure und die darauf beru hende elektive Farbung von Zellkernen in mikroskopischen Praparatum. Hoppe-Seylers Z. 135: 203-248.

Horstadius, S. (1950) The Neural Crest, Oxford U. P., London.

Karnovsky, M. J., and L. Roots (1964) A "direct-coloring" thiocholine method for cholinesterase. J. Histochem. Cytochem. 12: 219-221.

Kirby, M. L. (1988) Nodose placode contributes ectomesenchyme to the heart in the absence of cardiac neural crest. Cell Tissue Res. (in press).

Kirby, M. L., and D. E. Stewart (1983) Neural crest origin of cardiac ganglion cells in the chick embryo: Identification and extirpation. Dev. Biol. 97: 433-443.

Kirby, M. L., and D. E. Stewart (1984) Adrenergic innervation of the developing chick heart: Neural crest ablations to produce sympathetically aneural hearts. Am. J. Anat. 171: 295-305.

Kirby, M. L., T. F. Gale, and D. E. Stewart (1983) Neural crest cells contribute to normal aorticopulmonary septation. Science 220:1059_ 1061.

Kirby, M. L., K. L. Turnage, and B. M. Hays (1985a) Characterization of conotruncal malformation following ablation of "cardiac" neural crest. Anat. Rec. 213: 87-93.

Kirby, M. L., R. S. Aronstam, and J. J. Buccafusco (1985b) Changes in cholinergic parameters associated with failure of conotruncal septation in embryonic chick hearts after neural crest ablation. Circ. Res. 56: 392-401.

Kirby, M. L., D. C. Conrad, and D. E. Stewart (1987) Increase in the cholinergic cardiac plexus in sympathetically aneural chick hearts. Cell Tissue Res. 247: 489-496.

Landis, S. C., and D. Keefe (1983) Evidence for neurotransmitter plasticity in vivo: Developmental changes in properties of cholinergic sympathetic neurons. Dev. Biol. 98: 349-372.

LeDouarin, N. M. (1982) The Neural Crest, Cambridge U. P., London.

LeDouarin, N. M. (1986) Cell line segregation during peripheral nervous system ontogeny. Science 231: 1515-1522.

LeDouarin, N. M., J. Fontaine-Perus, and G. Couly (1986) Cephalic ectodermal placodes and neurogenesis. Trends Neurosci. 9: 175-180.

McKee, G. J., and M. W. J. Ferguson (1984) The effects of mesencephalic neural crest cell extirpation on the development of chicken embryos. J. Anat. 139: 491-512.

Narayanan, C. H. (1970) Apparatus and current techniques in the preparation of avian embryos for microsurgery and for observing embryonic behavior. Bioscience 20: 868-871.

Narayanan, C. H., and Y. Narayanan (1980) Neural crest and placodal contributions in the development of the glosspharyngeal-vagal complex in the chick. Anat. Rec. 196:71-82.

Nishibatake, M., M. L. Kirby, and L. H.S. Van Mierop (1987) Pathogencsis of pcrsistent truncus arteriosus and dextroposed aorta in the chick embryo after neural crest ablation. Circulation 75: 255-264.

Patterson, P. H., and L. L. Y. Chun (1977) The induction of acetylcholine synthesis in primary cultures of dissociated rat sympathetic neurons. Dev. Biol. 56: 263-280.

Rickenbacher, J., and E. Muller (1979) The development of cholinergic ganglia in the chick embryo heart. Anat. Embryol. 155: 253-258.

Sternberger, L. A. (1979) Immunocytochemistry, Wiley, New York.

Wakley, G. K., and A. J. Bower (1981) The distal vagal ganglion of the hen (Gallus domesticus). A histological and physiological study. J. Anat. 132: 95-115.

Yntema, C. E., and W. S. Hammond (1945) Depletions and abnormalities in the cervical sympathetic system of the chick following extirpation of neural crest. J. Exp. Zool. 100: 237-263.

Zacchci, A. M. (1961) Lo sviluppo embrionale della guaglia giaponese. Arch. Ital. Anat. Embryol. 66: 36-62. 